Abstracta Iranica Abstracta Iranica

Revue bibliographique pour le domaine irano-aryen

Volume 25 | 2004

Comptes rendus des publications de 2002

\title{
« Anti-Immigrant Attitudes in the Socio-Political Life of a Siberian City, The Example of Irkutsk ». Inner Asia, 2 (2000), pp. 13-24.
}

\section{Stéphane A. Dudoignon}

\section{(2) OpenEdition}

Journals

Édition électronique

URL : http://journals.openedition.org/abstractairanica/5136

DOI : 10.4000/abstractairanica.5136

ISSN : 1961-960X

Éditeur :

CNRS (UMR 7528 Mondes iraniens et indiens), Éditions de l'IFRI

\section{Édition imprimée}

Date de publication : 15 mai 2004

ISSN : 0240-8910

Référence électronique

Stéphane A. Dudoignon, « « Anti-Immigrant Attitudes in the Socio-Political Life of a Siberian City, The Example of Irkutsk ». Inner Asia, 2 (2000), pp. 13-24. », Abstracta Iranica [En ligne], Volume 25 | 2004, document 318, mis en ligne le 15 mars 2006, consulté le 25 septembre 2020. URL : http://

journals.openedition.org/abstractairanica/5136; DOI : https://doi.org/10.4000/abstractairanica.5136

Ce document a été généré automatiquement le 25 septembre 2020.

Tous droits réservés 


\title{
" Anti-Immigrant Attitudes in the Socio-Political Life of a Siberian City, The Example of Irkutsk ». Inner Asia, 2 (2000), pp. 13-24.
}

\author{
Stéphane A. Dudoignon
}

L'étude des populations migrantes d'Asie Centrale et du Caucase dans la Fédération de Russie, en Sibérie en particulier, est l'un des fils rouges de la sociologie russe (voir les travaux de Sergej Panarin et de nombreux articles dans la revue moscovite Acta Eurasica). En effet, bien que les Sibériens soient dans leur grande majorité des immigrants, en l'occurrence de Russie centrale et d'autres régions de peuplement slave, la décennie qui a suivi la disparition de l'URSS a vu, parmi eux, la ré-émergence d'attitudes xénophobes auparavant latentes. La présente étude analyse le cas d'Irkoutsk et tente d'expliquer pourquoi l'hostilité de la population vernaculaire se concentre sur les migrants originaires du Caucase méridional et de Chine (les facteurs évoqués sont l'animadversion traditionnelle de populations pénétrées d'une éthique du travail, égalitariste, envers les «trading minorities"; l'articulation de ces minorités avec les stéréotypes locaux de l'étranger; enfin l'exploitation d'une xénophobie naissante par les politiciens locaux dans le cadre de leur stratégie électorale). D'un autre point de vue, l'auteur insiste sur le fait que les stratégies d'autoprotection mises en œuvre par les migrants, par les Chinois en particulier, contribuent aussi à limiter leurs possibilités d'intégration. 
INDEX

Thèmes : 12.3. Asie centrale

\section{AUTEURS}

STÉPHANE A. DUDOIGNON

Université Marc Bloch - Strasbourg 